\title{
Stool microflora in extremely low birthweight infants
}

\author{
Ira H Gewolb, Richard S Schwalbe, Vicki L Taciak, Tracy S Harrison, Pinaki Panigrahi
}

Division of
Neonatology-UMMS
Rm N5W68
Department of
Pediatrics
University of
Maryland School of
Medicine
22 South Greene Street
Baltimore
MD 21201-1554
USA
I H Gewolb
V L Taciak
P Panigrahi

Department of Pathology R S Schwalbe†

Pathology and Laboratory Medicine Service

Veterans Affairs

Maryland Health Care Systems

Baltimore, Maryland

R S Schwalbe†

T S Harrison

†Deceased

Correspondence to:

Dr Ira H Gewolb

Email:

igewolb@peds05.ab.umd.edu

Accepted 17 November 1998

\begin{abstract}
Aim-To serially characterise aerobic and anaerobic stool microflora in extremely low birthweight infants and to correlate colonisation patterns with clinical risk factors.

Methods-Stool specimens from 29 infants of birthweight $<1000 \mathrm{~g}$ were collected on days 10, 20, and 30 after birth. Quantitative aerobic and anaerobic cultures were performed.

Results-By day 30, predominant species were Enterococcus faecalis, Escherichia coli, Staphylococcus epidermidis, Enterbacter cloacae, Klebsiella pneumoniae, and Staphylococcus haemolyticus. Lactobacillus and Bifidobacteria spp were identified in only one infant. In breast milk fed (but not in formula fed) infants, the total number of bacterial species/stool specimen increased significantly with time (2.50 (SE 0.34$)$ on day $10 ; 3.13(0.38)$ on day $20 ; 4.27(0.45)$ on day 30$)$ as did quantitative bacterial counts; Gram negative species accounted for most of the increase. On day 30, significant inverse correlations were found between days of previous antibiotic treatment and number of bacterial species $(r=0.491)$ and total organisms/g of stool $(r=0.482)$. Gestational age, birthweight, maternal antibiotic or steroid treatment, prolonged rupture of the membranes, and mode of delivery did not seem to affect colonisation patterns.

Conclusions-The gut of extremely low birthweight infants is colonised by a paucity of bacterial species. Breast milking and reduction of antibiotic exposure are critical to increasing fecal microbial diversity.

(Arch Dis Child Fetal Neonatal Ed 1999;80:F167-F173)
\end{abstract}

Keywords: stool; premature infant; enteric bacterial colonisation; breast milk

There have been many studies of fecal flora in newborn infants, ${ }^{1-4}$ but most have focused on term infants. These studies, which often differ in the specifics of the colonisation patterns found, nevertheless suggest that the gastrointestinal tract of term infants (and adults) is colonised by a rich mixed flora of multiple aerobic and anaerobic strains. However, there is little detailed information regarding the overall microbial milieu, both aerobic and anaerobic, in preterm infants, especially in premature extremely low birthweight (ELBW) infants weighing $<1000 \mathrm{~g}$ at birth, who are at greatest risk of developing various infectious and gastrointestinal complications, such as necrotising enterocolitis(NEC). ${ }^{5}$

In vaginally delivered neonates bacteria begin to appear in the stool in the first day of life, with Escherichia coli and Enterococcus spp usually among the first, followed within the first 5 days by Bifidobacterium spp. By 10 days of age, most healthy full term neonates are colonised with a heterogeneous bacterial flora, ${ }^{3}$ with bifidobacteria predominating in breastfed infants and a more mixed flora in those fed formula. ${ }^{1}$ In contrast, the gut of a preterm infant, cared for in the relatively aseptic neonatal intensive care environment and usually receiving antibiotics shortly after birth, shows delayed colonisation with a limited number of bacterial species. ${ }^{6-9}$

Bacterial overgrowth by a limited number of species is more likely to occur in preterm infants, as these are colonised by few aerobic bacterial strains compared with term babies. ${ }^{610}$ In a previous study focusing on aerobic species of bacteria, we showed that the stools of preterm infants, with and without NEC, are colonised by an average of 2.5 aerobic species. ${ }^{6}$ The aggressive antibiotic treatment used in the care of sick preterm infants further interferes with normal intestinal colonisation patterns. ${ }^{10}$ We have found that in most bacteraemic infants with NEC, the same organism found in the blood was also cultured in the stool. ${ }^{6}$ As knowledge of the progression of fecal microbial colonisation patterns could be important in determining an infant's predisposition to bacterial invasion and could influence the choice of antibiotic cover, the objective of this study was to serially characterise the aerobic and anaerobic stool microflora in a cohort of premature infants weighing $<1000 \mathrm{~g}$ at birth.

\section{Methods}

Stool specimens from 29 infants weighing $<1000 \mathrm{~g}$ at birth were collected on days 10, 20, and 30 (all (SD2) days) postnatally. All infants $<1000 \mathrm{~g}$ were eligible for the study, providing stools could be obtained at the designated time points. Information on demographics, antibiotic use, and feeding practice were obtained prospectively and confirmed by subsequent chart review. Timing of initial feedings was at the discretion of the attending physician; feeds were begun using $20 \mathrm{cc} / \mathrm{kg}$ of either maternal milk or half strength premature formula and advanced by $20 \mathrm{cc} / \mathrm{kg} /$ day until full feeds $(150$ $\mathrm{cc} / \mathrm{kg} / \mathrm{day}$ ) were attained. Antibiotic treatment was also at the discretion of the attending physician. In the first week of life infants were treated with ampicillin and gentamicin or cefo- 
Table 1 Population characteristics

\begin{tabular}{lll}
\hline & Breast milk $(n=15)$ & Formula fed $(n=14)$ \\
\hline Birthweight & $814(117) \mathrm{g}$ & $747(136) \mathrm{g}$ \\
Gestational age & $26.4(2.2)$ weeks & $26.0(1.8)$ weeks \\
Mode of delivery & Vaginal 9, C-section 6 & Vaginal 9, C-section 5 \\
Duration of PROM & $40.8(53.0) \mathrm{h}$ & $46.1(120.2) \mathrm{h}$ \\
Maternal steroids & Yes 13 No 2 & Yes 9 No 5 \\
Maternal antibiotics & Yes 11 No 4 & Yes 11 No 3 \\
Duration of postnatal antibiotics & $11.6(6.5)$ days & $16.8(8.4)$ days \\
Initiation of feeding & $7.5(5.7)$ days & $8.5(3.6)$ days \\
Achievement of full feeds & $18.5(5.5)$ days & $21.4(6.6)$ days \\
Number not achieving full feeds in & & \\
$\quad$ & 4 & 4 \\
\hline first 30 days & & \\
\hline
\end{tabular}

Values are given as mean (SD).

taxime; empiric treatment after the first week of life was with vancomycin and cefotaxime. If fungal infection was suspected the initial agent of choice was Amphotericin B; erythromycin was used if ureaplasma infection was suspected or confirmed. In the case of documented infection, antibiotics were tailored to the sensitivity of the organism.

The limited quantity of stool precluded splitting the sample for transport in a specific anaerobic transport medium; sole transport in anaerobic transport medium was not performed due to the potential loss of recovery of obligate aerobic species. Specimens were placed in preweighed sterile $15 \mathrm{cc}$ screw top tubes and sterile saline was added to yield a final concentration (w/v) of $100 \mathrm{mg}$ of stool $/ \mathrm{ml}$. The sample was vortexed after the addition of sterile glass beads, resulting in a uniform suspension. Serial 10 -fold dilutions were performed by removing $100 \mu \mathrm{l}$ of suspension and adding it to a tube containing $0.9 \mathrm{ml}$ of sterile normal saline. Each sample $(100 \mu \mathrm{l})$ was plated on appropriate agar (see below) and enumerated.

Aerobic micro-organisms: Stool dilutions were plated on tryptic soy agar containing 5\% defibrinated sheep blood/MacConkey agar, which is selective for enteric Gram negative bacteria, and on phenylethyl alcohol (PEA) sheep blood agar, which is selective for Gram positive bacteria. Plates were incubated at $35^{\circ} \mathrm{C}$ in a $5 \% \mathrm{CO}_{2}$ incubator and examined at 24 and 48 hours. Micro-organisms were identified to the species level using the Vitek GNI (for Gram negative bacteria), GPI (for Gram positive bacteria), and Yeast cards (bioMèriux Vitek, Inc., Hazelwood, MO). API 20E (for Gram negative bacteria), API STAPH (bioMèriux Vitek) (for Gram positive, catalase positive bacteria), API 20 STREP (bioMèriux Vitek) (for Gram positive, catalase negative bacteria), or API 20C (bioMèriux Vitek) (for yeasts) were used as a secondary method of identification when the Vitek system failed to provide an acceptable identification.

Anaerobic bacteria: Stool dilutions were plated on a non-selective pre-reduced CDC base agar supplemented with Vitamin $\mathrm{K}_{1}$, haemin, and $5 \%$ defibrinated sheep blood (CDC anaerobic blood agar, Remel Laboratories, Lexena, KS). Inoculated plates were immediately placed into an anaerobic jar (BBL Gas Pack System, Becton Dickinson Microbiology Systems, Cockeysville, MD) and incubated at $35^{\circ} \mathrm{C}$. Plates were examined at 48 and 96 hours. Suspicious colo- nies displaying distinct morphologies were subcultured and incubated in both aerobic and anaerobic environments to confirm their requirement for an anaerobic atmosphere. Rapid ANA II (Innovative Diagnostic Systems, Norcross, GA) was used to identify obligate anaerobic bacteria.

The number of bacterial species in each stool sample and the total number of bacteria/g of stool were first compared over time in breast milk fed and formula fed infants, using repeated measures ANOVA with StudentNewman-Kuel's post-hoc test. Univariate regression, followed by backward stepwise multivariate regression analysis, were used to assess the relation of length of antibiotic treatment, birthweight, gestational age, total days on breast milk, length of time to start of breast milk feeding, maternal antibiotic and steroid treatment, and mode of delivery to numbers of fecal bacterial species/stool sample on day 30 . Patterns of colonisation of individual species were analysed using $\chi^{2}$ or McNemar analysis, where appropriate. The number of bacterial species, the individual species patterns, ratio of Gram positive and Gram negative species, and absolute numbers of bacteria/g of stool were used for comparison of the various groups. All statistical analyses were performed using SigmaStat (Jandel Scientific Software, San Rafael, CA).

This study was approved by the Institutional Review Board of the University of Maryland.

\section{Results}

Characteristics of our study sample are given in table 1. Fifteen infants received human milk (all these infants were fed their own mother's milk, which had been frozen and stored before feeding) and 14 were fed premature infant formula. Details on timing of initiation of feeding and attainment of full volume of feeding (in those infants who successfully discontinued intravenous feeds within the study period) are also given in table 1 . There were no significant differences between the two groups in any of the characteristics shown. Eight infants (4 breast milk, 4 formula fed) did not reach full feeding volumes even by day 30 of life. All infants received at least two days of postnatal antibiotic treatment in the first month of life.

When considering our entire patient population, the most commonly identified bacterial organisms on day 10 were Staphylococcus epidermidis, Staphylococcus haemolyticus, Enterococcus faecalis, and Klebsiella pneumoniae. Candida spp were seen in about $30 \%$ of stool samples on day 10. By day 30, the predominant species were $E$ faecalis, $E$ coli, $S$ epidermidis, Enterobacter cloacae, $K$ pneumoniae, and $S$ haemolyticus (table 2). There were significant changes in colonisation pattern by individual species of bacteria over time. By the end of the first month of life a significantly greater percentage of infant stools were colonised by $E$ cloacae (11\% at 10 days; $11 \%$ at 20 days; $39 \%$ at 30 days; $\mathrm{p}<0.05)$ and by $E$ coli $(14 \%$ at 10 days; $33 \%$ at 20 days; $43 \%$ at 30 days; $\mathrm{p}<0.05$ ). There was a trend to increased colonisation by E faecalis (29\% at 10 days; $52 \%$ at 20 days; $57 \%$ 
Table 2 Stool microflora

\begin{tabular}{|c|c|c|c|c|c|c|c|c|c|}
\hline \multirow[b]{2}{*}{ Bacterial species } & \multicolumn{3}{|c|}{ Day 10} & \multicolumn{3}{|c|}{ Day 20} & \multicolumn{3}{|c|}{ Day 30} \\
\hline & $\begin{array}{l}\text { Total } \\
n=29\end{array}$ & $\begin{array}{l}\text { Breast } \\
n=15\end{array}$ & $\begin{array}{l}\text { Formula } \\
n=14\end{array}$ & $\begin{array}{l}\text { Total } \\
n=27\end{array}$ & $\begin{array}{l}\text { Breast } \\
n=15\end{array}$ & $\begin{array}{l}\text { Formula } \\
n=12\end{array}$ & $\begin{array}{l}\text { Total } \\
n=28\end{array}$ & $\begin{array}{l}\text { Breast } \\
n=15\end{array}$ & $\begin{array}{l}\text { Formula } \\
n=13\end{array}$ \\
\hline E faecalis & 8 & 5 & 3 & 14 & 10 & 4 & 16 & 10 & 6 \\
\hline E faecium & 1 & 0 & 1 & 1 & 0 & 1 & 0 & 0 & 0 \\
\hline S epidermidis & 17 & 10 & 7 & 15 & 10 & 5 & 12 & 6 & 6 \\
\hline S haemolyticus & 10 & 5 & 5 & 10 & 4 & 6 & 10 & 2 & 8 \\
\hline \multicolumn{10}{|l|}{ Other coagulase } \\
\hline (-) staphylococci & 3 & 0 & 3 & 3 & 1 & 2 & 4 & 3 & 1 \\
\hline$S$ aureus & 0 & 0 & 0 & 0 & 0 & 0 & 2 & 2 & 0 \\
\hline Kpneumoniae & 5 & 5 & 0 & 6 & 6 & 0 & 10 & 7 & 3 \\
\hline E cloacae & 3 & 2 & 1 & 3 & 2 & 1 & 11 & 7 & 4 \\
\hline$E$ aerogenes & 1 & 1 & 0 & 1 & 1 & 0 & 1 & 1 & 0 \\
\hline$P$ aeruginosa & 1 & 0 & 1 & 2 & 2 & 0 & 3 & 3 & 0 \\
\hline E coli & 4 & 1 & 3 & 9 & 3 & 6 & 12 & 7 & 5 \\
\hline Citrobacter spp & 2 & 1 & 1 & 3 & 3 & 0 & 4 & 3 & 1 \\
\hline Serratia $s p p$ & 1 & 0 & 1 & 1 & 0 & 1 & 0 & 0 & 0 \\
\hline Bacteroides spp & 3 & 1 & 2 & 2 & 1 & 1 & 3 & 1 & 2 \\
\hline Corynebacterium spp & 3 & 1 & 2 & 0 & 0 & 0 & 0 & 0 & 0 \\
\hline Veillonella $s p p$ & 0 & 0 & 0 & 0 & 0 & 0 & 2 & 2 & 0 \\
\hline Eikonella spp & 0 & 0 & 0 & 1 & 1 & 0 & 0 & 0 & 0 \\
\hline \multicolumn{10}{|l|}{ Propionobacterium } \\
\hline$s p p$ & 0 & 0 & 0 & 0 & 0 & 0 & 1 & 1 & 0 \\
\hline Bifidobacterium spp & 1 & 1 & 0 & 1 & 1 & 0 & 1 & 1 & 0 \\
\hline Lactobacillus spp & 1 & 1 & 0 & 0 & 0 & 0 & 1 & 1 & 0 \\
\hline \multicolumn{10}{|l|}{ Fungal species } \\
\hline Candida spp & 9 & 4 & 5 & 5 & 2 & 3 & 2 & 1 & 1 \\
\hline$M$ furfur & 3 & 2 & 1 & 0 & 0 & 0 & 0 & 0 & 0 \\
\hline
\end{tabular}

at 30 days; $\mathrm{p}=0.059)$. Colonisation with Candida spp significantly decreased with time, from $32 \%$ at day 10 to $7 \%$ at day $30(\mathrm{p}<0.05)$. The patterns of colonisation were similar in both breast milk and formula fed infants. Formula fed infants had a higher incidence of colonisation with $S$ haemolyticus on day 30 but not before that. Although breast milk fed infants initially had a higher incidence of $K$ pneumoniae colonisation, this was not significant by day 30 . Feeds were not introduced in most infants until several days after birth; thus day 30 patterns may be most revealing with respect to effects of different types of feeds on stool bacterial flora.

Lactobacillus spp and Bifidobacteria spp were identified only in one (breast milk fed) infant. In a previous pilot study using the same methods, with samples of stools from term breastfed infants, a variety of anaerobic bacterial species were recovered in virtually all stool specimens (data not shown), reinforcing our impression that the preterm infants' anaerobic microflora were underrepresented compared with those of term infants not treated with antibiotics.

Initial analysis involved total number of bacterial species in the stools. With the passage of time, total number of different species per specimen significantly increased (fig 1). The ratio of Gram negative to Gram positive species increased with time from $0.36: 1$ at day 10 to $0.87: 1$ at day $30(\mathrm{p}<0.05)$. Type of feed seemed to be critical in accounting for the significant increase in species number with time. There was no significant change in the number of fecal bacterial species over the first month of life in infants eventually fed with premature infant formula; however, infants who were fed breast milk (even if human milk feeds were not introduced in the first week of life) had significantly more bacterial species in their stools on day 30 (4.27 (SE 0.45)) than on day 10 (2.50 $(0.34))$ or day $20(3.13(0.38)$ ) (ANOVA; $\mathrm{p}<0.001)$, and on days 20 and 30 had

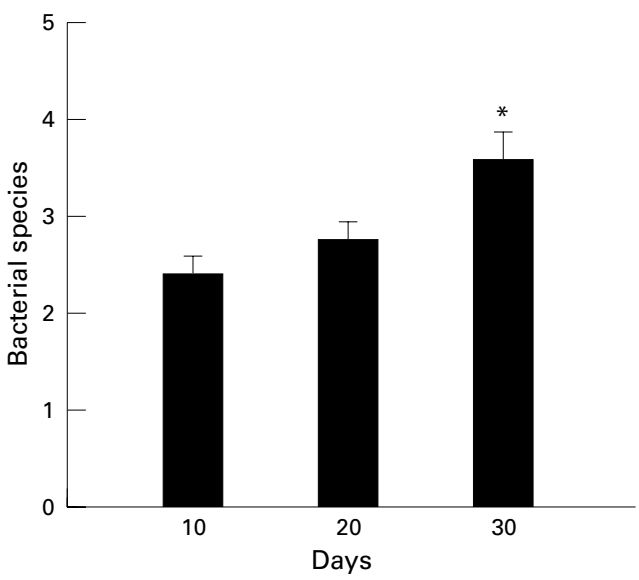

Figure 1 Total number of bacterial species in stools of extremely low birthweight infants over the first 30 days of life. ${ }^{\star} p<0.001$ ANOVA; ${ }^{\star \star} p<0.01$ vs day 10, day 20. In this and all subsequent figures, the error bars represent within subject SEM.

significantly more stool species than did formula fed infants (fig 2). This increase in total species number in breast milk fed infants was accounted for by a greater increase in number of Gram negative species (0.714 (SE $0.221)$ on day 10 to $2.133(0.274)$ on day 30 ; $\mathrm{p}<0.001)$ compared with formula fed infants (0.571 (0.228) on day 10 to $1.077(0.239)$ on day $30 ; \mathrm{p}=0.08)$. Gestational age and birthweight did not correlate with number of fecal bacterial species on either day 10 or day 30 , perhaps because of the narrow range of gestational age and birthweight in this select study population.

There was a significant inverse correlation between the number of days of antibiotic treatment in the first month of life and the number of bacterial species $(\mathrm{r}=0.491 ; \mathrm{p}=0.007)$ and the total number of organisms $(r=0.482 ; p=0.008)$ in the day 30 stool samples (figs 3 and 4).

Mode of delivery (caesarean or vaginal) did not affect fecal species number in the day 10 stool sample. Maternal antibiotic and steroid 
treatment did not seem to affect the number of bacterial species colonising their infants' stools at the various times studied; but most mothers

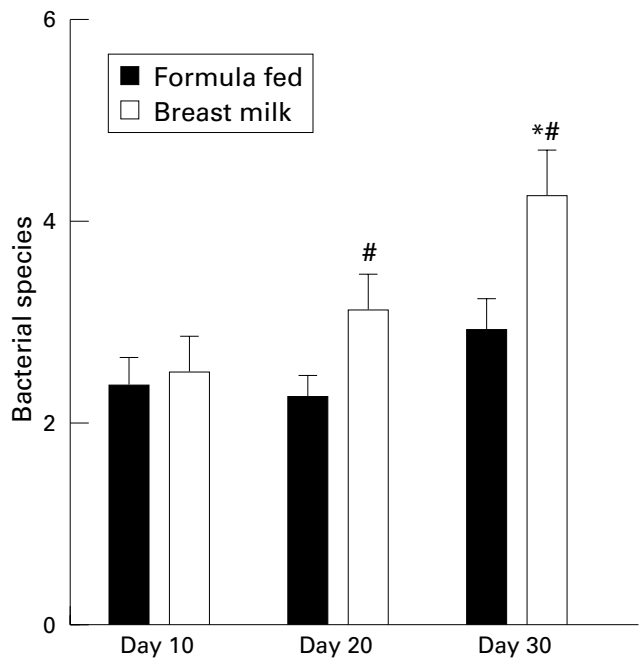

Figure 2 Number of bacterial species over time in breast milk and formula fed preterm infants. ${ }^{*} p<0.01$ vs. day 10 and day 20 breast milk fed infants; $\# p<0.05$ vs same day formula fed infants.

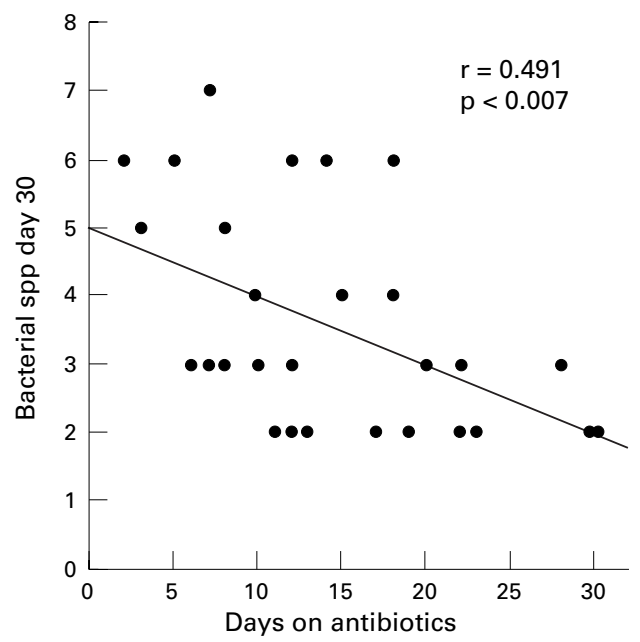

Figure 3 Number of bacterial species per day 30 stool sample is inversely correlated with days of antibiotic exposure.

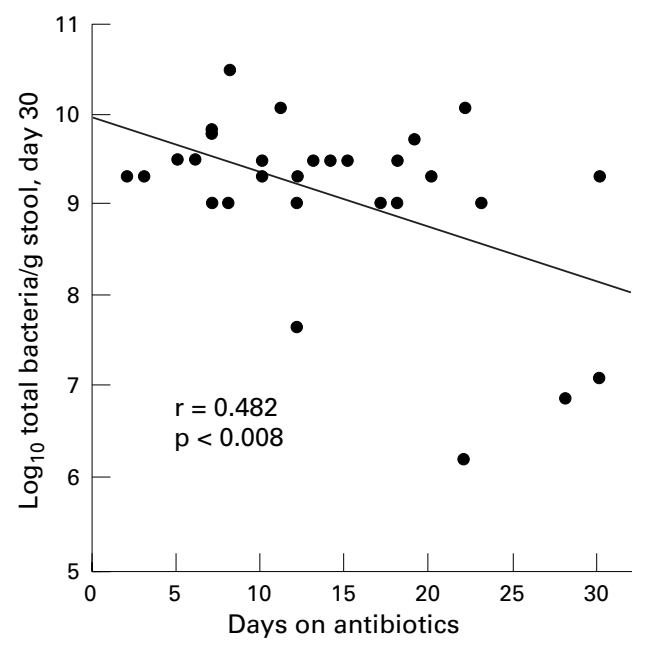

Figure $4 \log _{10}$ quantitative bacterial organisms/g of stool on day 30 as a function of days of antibiotic treatment. received steroids and/or antibiotics, so we could not definitively exclude an effect. Duration of rupture of membranes also did not affect species number in the day 10 sample.

The above univariate analyses suggested that decreased antibiotic exposure and introduction of breast milk feeds correlated with more fecal bacterial species on day 30 . This was confirmed by backward stepwise multivariate regression analysis using number of stool bacterial species on day 30 as the dependent variable, and birthweight, gestational age, maternal antibiotic treatment, maternal steroid treatment, mode of delivery, days of antibiotic treatment, days receiving breast milk (formula fed $=0$ ), and days to introduction of breast milk (formula fed designated as $=30$ (the total number of days in the study)) as independent variables in the model. Of these variables, only days of antibiotic exposure (inverse relation), and days receiving breast milk (positive relation) and days before introduction of breast milk (inverse relation) were predictive of number of bacterial species on day $30 \mathrm{r}^{2}=$ $0.446 ; \mathrm{p}=0.002$ ). When only breast milk infants were analysed by stepwise regression analysis, duration of breast milk feeds and time to initiation of breast milk feeding (as well as duration of antibiotic treatment) remained significant predictors $\left(r^{2}=0.710 ; p=0.009\right)$, reinforcing the previous analysis.

In addition to the above analyses involving species number, we also performed quantitative analysis of bacterial counts in our stool specimens. Analysis of the entire population showed a significant increase in the total number of organisms/g of stool on day 30 (mean $\log _{10}=9.08$ (SE 0.18) compared with day $10(7.22(0.54))$ or day 20 counts (7.95 $(0.52))(p<0.002)$. This difference in total bacterial count was again primarily accounted for by a significant absolute increase in number of Gram negative organisms (RM ANOVA; $\mathrm{p}<0.05)$. The change in total number of bacteria on days 10 and 30 was more pronounced in breast milk fed infants (mean $\log _{10}$ on day $10=$ 6.83 (SE 0.87); on day $20=8.52(0.63)$; on day $30=9.25(0.27)$; one way RM ANOVA $\mathrm{p}<0.005$ ) than in formula fed infants (mean $\log _{10}$ on day $10=7.64(0.66) ;$ on day $20=7.24$ (0.86); on day $30=8.87(0.24)$; one way RM ANOVA $\mathrm{p}=0.14$ ). Again, significant increases in total Gram negative organisms accounted for most of the differences in both groups; total Gram positive organisms remained about the same in the formula fed infants but increased slightly in the breast milk fed babies. Nevertheless, at each time point there was no significant difference in total bacterial counts between the two groups (as opposed to the significant increases in species number on days 20 and 30 in the breast milk fed group). Thus the breast milk fed infants had a more diverse, but not necessarily larger, bacterial population than did their formula fed counterparts.

Only two infants in our study developed radiographically confirmed NEC (one died after perforation). Both these infants were formula fed (starting on days 8 and 9). One infant 
was colonised by $S$ epidermidis on day $10, S$ haemolyticus, E cloacae, and Staphylococcus simulans on day 20, and by $E$ cloacae and $S$ epidermidis in the day 30 stool (NEC developed on day 35 of life). The other was colonised by $E$ coli and $E$ faecalis on day 10 and by $E$ coli, E faecalis, and $S$ haemolyticus on the day 20 sample obtained shortly before the baby developed NEC, a pneumoperitoneum, and died.

\section{Discussion}

In term infants human milk promotes the growth of bifidobacteria and lactobacilli in the intestine, generating a very different gut flora from that seen after formula feeding. ${ }^{1}$ Hall et al found decreased numbers of lactobacilli in preterm infants (average birthweight $1440 \mathrm{~g}$ ); this reduction was correlated with previous antibiotic treatment and time spent in an incubator. Sakata et $a l^{11}$ noted that the establishment of bifidobacteria as the predominant fecal flora was delayed in seven very low birthweight infants when compared with controls, but most of these infants weighed $>1000 \mathrm{~g}$ at birth, only one was intubated, and only two received antibiotics (both after 2 weeks of life). The present study was designed to clarify the microbial ecology over the first month of life in ELBW infants over the first month of life under circumstances prevailing in most neonatatal intensive care units - that is, early and often prolonged antibiotic treatment, intubation, and intravenous alimentation, with oral feeds often delayed until clinical stability is established. Our data are consistent with previous findings of delayed establishment and decreased numbers of anaerobes in general and of lactobacilli and bifidobacteria in particular.

The results from this study underscore the paucity of bacterial species, especially lactobacilli and bifidobacteria, in the gut of ELBW infants in the first month of life, a time when most of these infants receive one or more courses of antibiotics. The fact that most ELBW infants are colonised by fewer than three species of bacteria by the 10th day of life (as opposed to the more complex/diverse pattern of colonisation seen in healthy term neonates) could possibly predispose to continued overgrowth of potentially pathogenic species, especially under antibiotic pressure. Our data indicate that lack of breast milk feeding and increased antibiotic use have separate but interactive negative effects on gut floral diversity. Exposure to multiple antibiotics seems to be the major factor in the overall reduction of antibiotic species in the preterm gut at all time points studied; introduction of breast milk feeding seems to favour a slightly more diverse flora over time, although the mechanism by which this occurs remains to be clarified.

The experience with germ free animals may be germane when discussing the microbial environment in preterm infants. If such animals are contaminated with a single bacterial strain, that organism can populate the gut in very high concentrations. ${ }^{12}$ Germ free pigs and guinea pigs can develop severe enteritis when removed from the germ free environment or when contaminated with a single species $^{13}$; protection can be afforded by prior seeding with elements of their normal stool flora. ${ }^{14}$ "Schaedler's Cocktail," a combination of harmless bacteria, is routinely used in raising specific pathogen free rodents; without such treatment, normal physiological development of the gut does not occur, and rodents become susceptible to infection with bacteria that would otherwise be considered non-pathogenic. ${ }^{15}$ Lactobacilli and bifidobacteria may have a role in preterm infants similar to that of Schaedler's Cocktail in germ free rodents. Bifidobacteria, lactobacilli, propionibacteria, and enterococci isolated from the guts of healthy infants have been shown to inhibit Clostridium botulinum in vitro. ${ }^{16}$ Pre-incubation with Lactobacillus acidophilus competitively excludes enterotoxigenic $E$ coli from Caco-2 cells. ${ }^{17}$ Of specific relevance to preterm infants, Barlow et al, noted that feeding maternal milk, oral immunoglobulin, or oral Lactinex (a commercial preparation containing Lactobacillus acidophilus and Lactobacillus bulgaricus) prevented gut injury in a hypoxic neonatal rat model of NEC. ${ }^{18}$

Bacterial infection and colonisation of the premature intestinal tract are likely to have a role in both the predisposition to and the pathogenesis of NEC. ${ }^{19}{ }^{20}$ There have been several studies of enteric flora in infants with NEC. Blakey et $a l^{1}$ found a decreased percentage of infants with NEC harbouring Bacteroides spp and lactobacilli, and an increased number colonised with Clostridium perfringens. Bell et $a l^{22}$ noted increased numbers of Gram negative bacteria (especially $E$ coli and Klebsiella spp) in infants with NEC. In contrast, in a prospective case-control study of endemic NEC, we were unable to demonstrate any significant associations between any single aerobic bacterial species and NEC. ${ }^{6}$ Eight children were bacteraemic; in seven the same organism was also present in the stool.

In a subsequent series of studies ${ }^{23}$ using the microbial isolates from our prospective epidemiological study ${ }^{6}$ we showed that coinfection with specific Gram positive bacterial species (obtained from infants without NEC) blocked adherence of Gram negative organisms in a Caco- 2 cell system and blocked $E$ coli induced gut mucosal injury in a weanling rabbit ileal loop model. We also recently reported that non-toxigenic $E$ coli strains can translocate enterocyte monolayers, a phenomenon that can also be blocked by the aforementioned specific Gram positive bacteria isolated from healthy infants. ${ }^{24}$ Thus we hypothesised that a specific microbial ecology or colonisation pattern and lack of certain protective Gram positive species, especially in the sparsely colonised immature gut, may be critical in the pathogenesis of NEC because they permit overgrowth of potentially pathogenic species. In other words, the presence of specific organisms may be less important than the combinations of bacteria present, which could influence such things as microbial adherence, toxin production, and carbohydrate metabolism. 
The methods used in our study were appropriate for recovery of anaerobic bacteria that are found in the human intestine. Feces were not placed in anaerobic transport media before culture but were directly taken to the laboratory for plating, to preclude growth in the transport medium, which might have affected the quantitative analysis. The presence of other organisms in the stool also creates a microaerophilic environment by their own metabolism, which would support the survival of anaerobes during the time needed for transport. In addition, Bifidobacterium spp and Lactobacillus spp are microaerophilic bacteria which will grow aerobically in a $\mathrm{CO}_{2}$ enriched atmosphere that is similar to the methods used in this study. ${ }^{25}$ Indeed, in those cases when we did isolate Bifidobacterium spp or Lactobacillus spp from our samples, they were recovered from both anaerobic and aerobic plates. These strains were also recovered at multiple sampling intervals from the one preterm patient who harboured them, suggesting that the absence of these species in other infants is unlikely to be artefactual. Breast milk samples were not cultured before use, so the possibility that some of the additional diversity seen in breast milk fed infants is the result of inadvertent contamination with maternal skin bacteria ( $S$ epidermidis, for example) has not been entirely eliminated. However, recent studies ${ }^{26}$ indicate that coagulase negative staphylococci are by far the most prevalent contaminants of expressed breast milk, whereas the increased species diversity in our breast milk fed group resulted from an overall increase in Gram negative species rather than staphylococci. The use of banked human milk or improperly collected human milk could introduce additional variables.

Factors that can increase the diversity of microbial colonisation in preterm infants may be of interest. Our finding of an inverse relation between days on antibiotics and bacterial diversity and number suggest that reduction of routine antibiotic exposure and perhaps decreased length of therapy for some nosocomial infections (such as those caused by coagulase negative staphylococci) may promote fecal microbial diversity.

Attempts have been made to modify gastrointestinal flora in human neonates. Reuman et $a l^{27}$ introduced oral feedings of $10^{9} \mathrm{~L}$ acidophilus within 72 hours of delivery. Lactobacilli were recovered in stools of $13 / 15$ infants receiving supplementation vs 3/15 in controls. No qualitative difference was found in the isolation rate of Gram negative bacteria. Mautone et $a l^{28}$ found a reduction in Gram negative flora and a percentage increase in Gram positive bacilli after feeding a mix of Bifidobacterium bifidum and $L$ acidophilus to a group of 77 neonates. Bennett et $a l^{29}$ showed that oral bifidobacteria and lactobacilli could be cultured from the feces of term infants for several days after such treatment was discontinued. A fermented infant formula containing viable bifidobacteria increased colonisation with bifidobacteria at 1 month of age in healthy term infants. ${ }^{30}$ Early administration of Bifidobacterium breve to 91 very low birthweight infants effectively colonised the immature bowel and resulted in decreased aspirated air volume from the stomach and increased feeding volume and weight gain. ${ }^{31}$ These studies, in conjunction with data indicating a paucity of stool bacterial species and a lack of a diverse fecal bacterial flora including bifidobacteria and lactobacilli, suggest that further exploring the possibility of modifying gut flora in the preterm infant may be worthwhile.

This work was funded in part by a SRIS grant from the University of Maryland (IHG) and NICHD \# HD-29735 (PP).

1 Yoshioka H, Iseki K, Fujita K. Development and differences of intestinal flora in the neonatal period in breast-fed and bottle-fed infants. Pediatrics 1983; 72:317-21.

2 Hall MA, Cole CB, Smith SL, Fuller R, Rolles CJ. Factors influencing the presence of fecal lactobacilli in early infancy. Arch Dis Child 1990; 65:185-8.

3 Long SS, Swenson RM. Development of anaerobic fecal flora in healthy newborn infants. F Pediatr 1977;91:298-301.

4 Lundequist B, Nord CE, Winberg J. The composition of faecal microflora in breastfed and bottle fed infants from birth to eight weeks. Acta Paediatr Scand 1985;74:45-51.

5 Uauy RD, Fanaroff AA, Korones SB, Phillips EA, Philips JB, Wright LL. Necrotizing enterocolitis in very low birth weight infants: Biodemographic and clinical correlates. $\mathcal{F}$ Pediatr 1991;119:630-8.

6 Gupta S, Morris JG, Panigrahi P, Nataro JP, Glass RI, Gewolb IH. Endemic necrotizing enterocolitis:lack of association with a specific infectious agent. Pediatr Infect Dis f 1994; 13:725-34.

7 Mackowiak PA. The normal microbial flora. $N$ Engl f Med 1982;307:83-93.

8 Bennet R, Eriksson M, Nord CE, Zetterstrom R. Fecal bacterial microflora of newborn infants during intensive care management and treatment with five antibiotic regimens. Pediatr Infect Dis f1986;5:533-9.

9 Lawrence G, Bates J, Gaul A. Pathogenesis of neonatal necrotizing enterocolitis. Lancet 1982;i:137-9.

0 Goldman DA, Leclair J, Macone A. Bacterial colonisation of neonates admitted to an intensive care environment. $\mathcal{f}$ Pediatr 1978;93:288-93.

11 Sakata H, Yoshioka H, Fujita K. Development of the intestinal flora in very low birth weight infants compared to normal full-term infants. Eur f Pediatr 1985;144:186-90.

12 Gibbons RJ, Socransky SS, Kapsimalis B. Establishment of human indigenous bacteria in germ free mice. 7 Bacteriol 1964;88:1316-23.

13 Coates ME, Gustafsson BE. The germ free animal in biomedical research. London: Pub Lab Animals Ltd., 1984.

14 Collins FM, Carter PB. Growth of salmonellae in orally infected germfree mice. Infect Immunol 1978;21:41-7.

15 Harp JA, Chen W, Harmsen AG. Resistance of severe combined immunodeficient mice to infection with Cryptosporidium parvum: the importance of intestinal microflora. Infect Immunol 1992;60:3509-12

16 Sullivan NM, Mills DC, Riemann HP, Arnon SS. Inhibitions of growth of Clostridium botulinum by intestinal microflora isolated from healthy infants. Microbial Ecology in Health and Disease 1988;1:179-92.

17 Chauviere G, Coconnier MH, Kerneis S, DarfeuilleMichaud A, Joly B, Servin AL. Competitive exclusion of diarrheagenic Escherichia coli (ETEC) from human diarrheagenic Escherichia coli (ETEC) from human enterocyte-like Caco-2 cells by heat

18 Barlow B, Santulli TV, Heird WC, Pitt J, Blanc WA, Schullinger JN. An experimental study of acute neonatal enterocolitis-the importance of breast milk. F Pediatr Surg 1974;9:587-94

19 Kosloske AM. A unifying hypothesis for the pathogenesis and prevention of necrotizing enterocolitis. $\mathcal{F}$ Pediatr 1990;117:S68-74.

20 Kliegman RM. Neonatal necrotizing enterocolitis: Implications for an infectious disease. Pediatr Clin North Am 1979;26:327-44.

21 Blakey JL, Lubitz L, Campbell NT, Gillan GL, Bishop RF, Barnes GL. Enteric colonization in sporadic neonatal necrotizing enterocolitis. $f$ Pediatr Gastroenterol Nutr necrotizing en $1985 ; 4: 591-5$.

22 Bell MJ, Feigin RD, Ternberg JL, Brotherton T: Evaluation of gastrointestinal microflora in necrotizing enterocolitis. $\mathcal{F}$ Pediatr 1978;92:589-91.

23 Panigrahi P, Gupta S, Gewolb IH, Morris JG. Occurrence of necrotizing enterocolitis may be dependent on patterns of bacterial adherence and intestinal colonization: Studies in Caco-2 tissue culture and weanling rabbit models. Pediatr Res 1994;36:115-21

24 Panigrahi P, Bamford P, Horvath K, Morris JG, Gewolb IH. Escherichia coli transcytosis in a Caco-2 cell model:Implications in neonatal necrotizing enterocolitis. Pediatr Res 1996;40:415-21.

25 Sutter R, Citron DM, Edelstein MAC, Finegold SM, eds. Processing clinical specimens and isolation and identification procedures. In: Wadswoth Anaerobic Bacteriology Manual. 4th edn. Star Publishing Co., Belmont, CA, Manual. 4th 
26 El-Mohandes AE, Schatz V, Keiser JF, Jackson BJ. Bacterial contaminants of collected and frozen human milk used in an inter

27 Reuman PD, Duckworth DH, Smith KL, Kagan R, Bucciarelli RL, Ayoub EM. Lack of effect of Lactobacillus on gastrointestinal bacterial colonization in premature infants. Pediatr Infect Dis ₹ 1986;5:663-8.

28 Mautone A, Monno R, Palmieri P, Brandonisio O. Colonizzazione indotta di Bifidobacterium bifidum e di Lactobacillus acidophilus in neonati ospedalizzati. Minerva Pediatrica 1982; 34:245-50.
29 Bennet R, Nord CE, Zetterstrom R: Transient colonization of the gut of newborn infants by orally administered
bifidobacteria and lactobacilli. Acta Paediatr 1992; bifidobacteria and lactobacilli. Acta Paediatr 1992; 81:784-7.

Langhendries JP, Detry J, Van Hees J, et al. Effect of a fermented infant formula containing viable bifidobacteria on the fecal flora composition and $\mathrm{pH}$ of healthy full-term infants. F Pediatr Gastroenterol Nutr 1995;21:177-81.

31 Kitajima H, Sumida Y, Tanaka R, Yuki N, Takayama H, Fujimura M. Early administration of Bifidobacterium breve to preterm infants: randomised controlled trial. Arch Dis Child 1997; 76:F101-7. 